\section{PROPHYLACTIC VACCINATION AGAINST EPIDEMIC MENINGITIS}

\section{A SUPPLEMENTARY NOTE}

\section{J. H. BLACK, M.D. \\ DALLAS, TEXAS}

In April, 1912, Dr. Abraham Sophian, then of the Research Laboratory of the New York Board of Health, and I conducted a series of experiments to determine, as well as laboratory methods will permit, the value of prophylactic vaccination against epidemic meningitis. Injections of meningococcic vaccine were made on ten medical students who volunteered for the work. The details of this work with the results obtained were reported in THE JOURNAL. ${ }^{1}$

Eleven months later I repeated these experiments to determine what, if any, immunity could be demonstrated after the lapse of this time. Eight of the original ten vaccinated students were accessible. The technic used in the complement-fixation studies was identical with that formerly reported. The results of this study were reported in THE Journal. ${ }^{2}$

With the effort to make this work as nearly complete as possible, I undertook in May, 1914, twelve and twenty-four months from the second and first examinations, respectively, a repetition of the complementfixation studies. Table 1 shows the results obtained. It will be seen that all but one of the seven students at hand gave decided fixation in a dilution of $1: 20$, this, two years after the date of vaccination.

\section{TABLE 1.-COMPLEMENT-FIXATION}

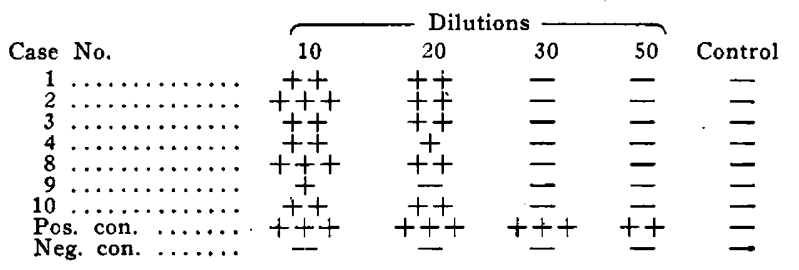

\section{TABLE 2.-COMPLEMENT-FIXATION}
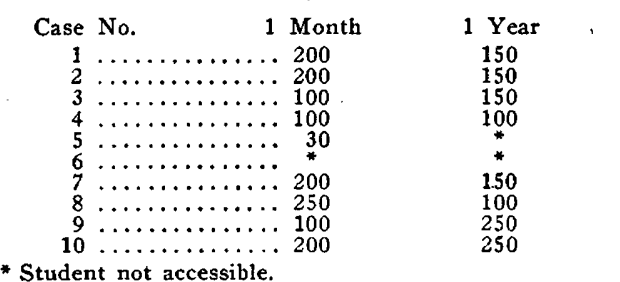

2 Years
20
20
20
20
$*$
$*$
20
10
20

Table 2 is a comparison of the fixation of each student at one month, one year, and two years, respectively, after vaccination. The figures in each column refer to the highest dilution at which fixation was obtained.

While it is recognized that experimental vaccination of healthy individuals in the absence of an epidemic and the detection of immune bodies in their blood is an indirect way of proving its efficacy, and that the method must finally be judged by its clinical application, we feel that we are justified in drawing the following conclusions from these studies:

1. Prophylactic vaccination produces a high degree of immunity in most cases, this immunity being

1. Sophian, Abraham, and Black, J. H.: Prophylactic Vaccination Against Epidemic Meningitis, The Journal A. M. A., Aug. 17, 1912 p. 527 . p. 2. Black, J. H.: Prophylactic, The Journal A. M. A., April 26, 1913,
p. 1289 . demonstrable at the end of two years. It seems a justifiable conclusion that most persons prophylactically vaccinated may safely consider themselves immune for at least two years. Exceptions to this will, of course, be found.

2. Some individuals may show an actual increase in immune bodies at the end of one year over those demonstrable soon after vaccination.

3. Fixation occurred with the serum of the positive control who has recovered from meningitis, but this fixation did not reach as high dilutions as did that of some of those vaccinated. ${ }^{2}$ This has previously been found also in some others recovered from the disease.

4. Experimental evidence warrants us in concluding that prophylactic vaccination is a measure of the greatest value in the control of epidemic meningitis.

\section{TRICHOTILLOMANIA}

Richard L. Sutton, M.D., Kansas City, Mo.

We are indebted to the French school of dermatology, and particularly to Besnier,' Hallopeau, ${ }^{2}$ Henri Fournier ${ }^{3}$ and Brocq, ${ }^{4}$ for the recognition and classification of the peculiar family of neurodermatoses which is represented by trichotillomania and dermatothlasia.

Trichotillomania, the "trichomanie" of Besnier, is an affection which is characterized by an abnormal desire on the part of an otherwise apparently sane individual to extract forcibly one or more of his own hairs. ${ }^{5}$ The impulse is seldom cyclic, but is as sudden as it is uncontrollable, and Raymond's designation of "tic de l'epilation" is not an inappropriate one. The scalp, the eye-brows and lashes, and the beard are the parts most frequently attacked.

Dermotothlasia is a somewhat similar morbid state in which the affected individual possesses an ungovernable desire to rub, scratch or irritate the skin on one or several parts of the body.

\section{TRICHOTILLOMANIA}

Recently I had an opportunity to study two typical examples of trichotillomania.

CASE 1.-The first case occurred in a married woman of 27, an American by birth and a housekeeper by occupation, referred to me by Dr. Charles W. Gosney of Kansas City. The patient had always been of a nervous temperament, but her family history was negative insofar as nervous or cutaneous ailments were concerned. Two years prior to the time of consultation she first became aware of the fact that she had acquired the habit of frequently jerking hairs out of her eyebrows whenever she was worried or subjected to prolonged periods of excitement. Despite her efforts to combat the practice, the habit grew stronger instead of weaker. She had never suffered from pruritus or other irritation of the supraorbital regions, and could not account for the propensity to remove the hair from these particular localities. The attacks were confined principally to the inner extremities of the brows, where the hairs protruded forward and were easy to grasp. It did not appear to matter which hand was used in the process of extraction. As the patient described it, she would have a sudden, intense desire to pull out one of the hairs (normal individuals probably experience a somewhat analogous sensation at times regarding one of the stiff vibrissae of the nose), and a second later she would be gazing at the freshly extracted appendage with its partially adherent root sheath. 1. Besnier, E.: Monatsh. f. prakt. Dermat., 1889, ix, 572.
2. Hallopeau: Ann. de dermat. et de syph., 1889, Series 2, x, 440; Bull. Soc. franc. de dermat. et de syph., 1891, ii, 157; Ann. de dermat.

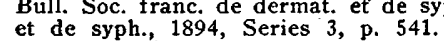

3. Fournier, Henri: Jour. malad. cutan. et syph., April, 1898.

3. Fournier, Henri: Jour. malad. cutan. et syph., April, 1898. 1907 ii, 398; Jour. des pract., March 26, 1898 .

5. "La trichotillomanie consiste essentielment en une impulsion qui pousse les subjects a arracher des poils; ce besoin de pratiquer l'avul. sion constitute une veritable manie, et nous l'avons observee sans
qu'il y ait de prurit notable" (Brocq). 
The patient was a muscular young woman, with brown hair and eyes. Her chin was firm and well set, and in her general appearance there was nothing suggestive of hysteria or other mental ill-balance. The skin of the face was smooth and unmarked, with but a slight trace of seborrhea. The lower lashes were normal, but the upper were sparse and straggling, and it is exceedingly probable that the patient had removed many of these also. The eye-brows were apparently much abbreviated, and set wide apart, a space of more than $11 \mathrm{~cm}$. separating the inner extremities. At a few meters' distance the impression given an experienced observer was

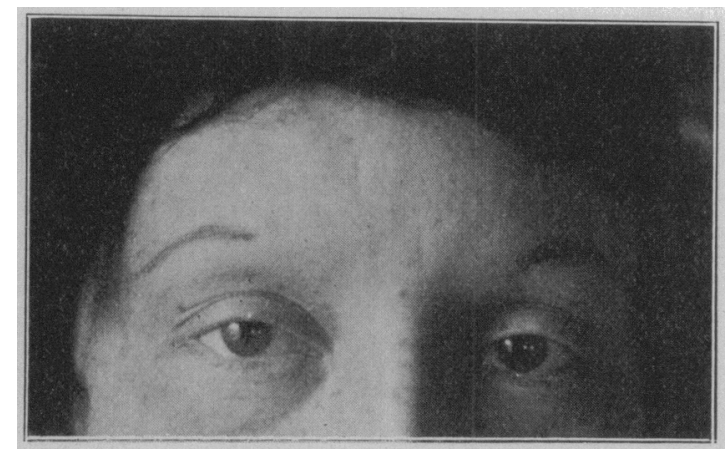

Fig. 1.-Trichotillomania, Case 1, showing absence of upper lashes and inner extremities of eyebrows.

that of a bilateral alopecia areata of remarkable symmetry. On closer scrutiny, however, it was found that a broad, indistinct, bluish band projected inward for a considerable distance from the terminus of each brow. When these areas were examined with a magnifying glass they were found to be thickly studded with new hairs, many of which were just reaching the surface. The patient stated that as soon as a fresh shaft was of sufficient length to be grasped it was promptly extracted. The hairs in the outer portions of the brows were undisturbed, and the smooth, regular manner in which they were arranged, together with the apparently normal condition of the underlying skin, indicated that the patient's statement regarding the absence of pruritus was correct.

CAse 2.-The second patient was a schoolboy, aged 14, a native and resident of Kansas, who was referred to me by Dr. H. P. Ball of Kansas City. This patient has been under the care of Dr. B. M. Barnett of Rosedale, Kansas, for some time, and I am indebted to Dr. Barnett for the privilege of reporting it here. The neurologic history of the family is negative. There is one other child, a boy of 9 . He is mentally and physically normal. The patient has always been of a high strung, nervous temperament. When a baby he sucked his fingers incessantly. Later, he chewed his nails. He has been a "mouth breather" nearly all his life. Although not very robust, he escaped the more serious of the diseases of childhood, and has never had a more serious disorder of the nervous system than the "habits" above mentioned. He has never suffered from headaches or eye strain, and there is no history of eczema or pruritus of the scalp.

On examination the patient was found to be a slender, fragile boy, with a shrunken chest and a retreating chin. The palate was arched and misshapen, and the teeth poorly aligned. The eye-brows and lashes were unaffected. The hair on the top and right side of the head was normal, but on the left side practically all of the stiff shafts were gone, and only the soft, fuzzy tips of the downy new growth were to be seen. The denuded skin was soft, smooth and pliable, with no trace of scratch marks.

The little patient stated that it was impossible for him to resist the impulse which occasionally prompted him to jerk out the stiffer hairs. The tendency was greatest whenever he became worried or excited.

\section{TREATMENT}

In the first case, rest and freedom from worry, with liquor potassii arsenitis in gradually increased doses, internally, appeared to benefit the patient's condition. The application of various anti-pruritics, such as phenol, menthol, camphor and tar, apparently had no effect whatever. Hallopeau has suggested the use of gutta percha and similar dressings of an impervious character in these cases. Probably a better plan would be to ameliorate the habit by keeping the hair shaved off for a period of several months. This patient absolutely refused to allow the adoption of this measure, but I hope to give it a trial later on. Dr. Barnett reports that the second patient has been considerably benefited by the use of tonics. principally arsenic.

If one excludes Brocq's "acne excoriee des jeunes filles," as I think we should, true examples of dermatothlasia are exceedingly rare. Occasionally, however, one encounters a case of acaraphobia closely bordering on dermatothlasia. The following is an example:

\section{DERMATOTHLASIA}

CASE 3.-M. P., female, spinster, physician, aged 52. This patient first consulted me in October, 1909, regarding a disorder which at first glance appeared to be a generalized pruritus. The disease had begun, three years before, with a slight itching of the skin on various parts of the body, and had continued at irregular intervals ever since. The integument was soft, moist and apparently normal, and there were no signs of senile atrophy. The urine contained considerable quantities of indican, but no albumin or sugar. The bloodpressure was not excessive. The hemoglobin was usually below 70 per cent. The cranial hair was short, dry and matted, and the scalp rough and scaly, probably a result of frequent and violent manipulation with the patient's nails. There were no signs of seborrhea or seborrheic dermatitis on the face or over the sternum. There was no hepatic tenderness, and the patient was not jaundiced. The woman's principal complaint was that she had "bugs" in her skin. She would suddenly pounce on some small area, most oftcil

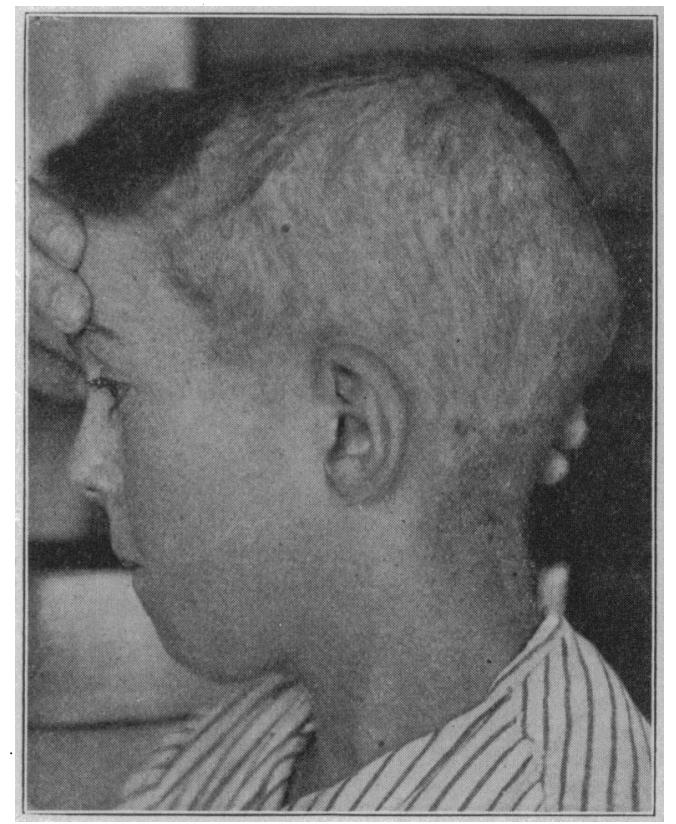

Fig. 2.-Trichotillomania, Case 2, showing extent of hair loss on left side of head.

located on the scalp or limbs, rub vigorously for a few moments, and then triumphantly announce that she had captured one or more insects, and that they were contained in the minute, tightly rolled, oat-grain-like mass of epithelial debris that she had detached. Innumerable negative examinations of the material made no impression whatever on her, but left her as firmly convinced as ever that her integument was inhabited by a new species of small but exceedingly industrious insect that would eventually prove her undoing. On subjects other than this ailment the patient's mind was unaffected. She suffered but little from pruritus, but explained that the sudden development of a slight sensation 
of formication in the involved areas always precipitated the attack of rubbing. The forcible removal of a few of the outermost corneous layers invariably had a soothing effect on her mind, and after she had carefully burned the material and its supposedly dangerous contents, she was perfectly at ease, sometimes for hours. The patient was under observation for three years, and during that time almost every conceivable remedy was tried, always without relief. When last seen, the patient's condition was practically the same as at the time of the first consultation.

Lathrop Building.

\section{DERMATOLYSIS}

WITH REPORT OF TWO CASES

\section{Wm. W. Cadbury, M.D., Canton, China}

Recently I have come across two typical cases of the rare affection known as dermatolysis. The condition is defined diameter of $1 \mathrm{t} / 2$ inches (Figs. 1,2 and 3). The patient was below the average in intelligence and somewhat self-conscious of his peculiar appearance. He was discharged from the hospital April 7, in practically the same condition as on admittance.

Description of the cutaneous flap: This peculiar hypertrophic growth begins on the left side of the scalp at a poin above the level of the eyebrows, falls down over the face entirely covering the left ear, which projects from the inner surface of the flap. It descends to the shoulder on which it rests. The flap measures 9 inches in length by 8 inches in width. The patient declares that at birth the flap was about 2 inches in length and has gradually been extending in size. In every way the skin resembles redundant scalp tissue. The external surface is studded with hair follicles from which recently clipped hairs project. The inner and external surfaces may be readily rubbed over each other. The color of the skin of the flap, like that of the rest of the body, is rather deeply pigmented. The loose skin may be readily

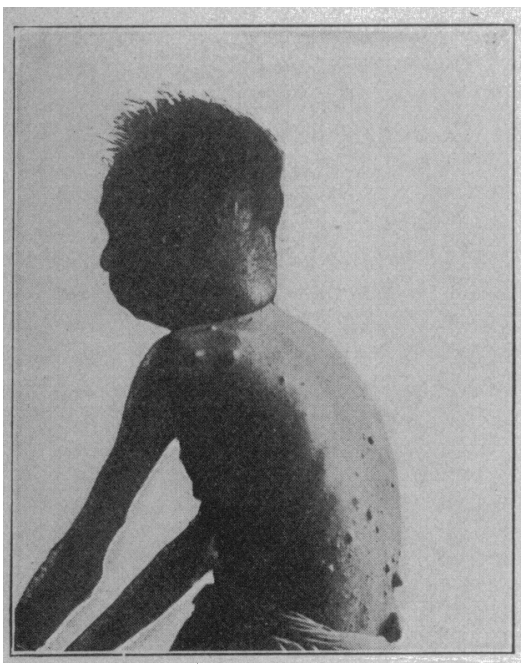

Fig. 1-Patient in Case 1. Note flap of skin and fibrous tumors on back.

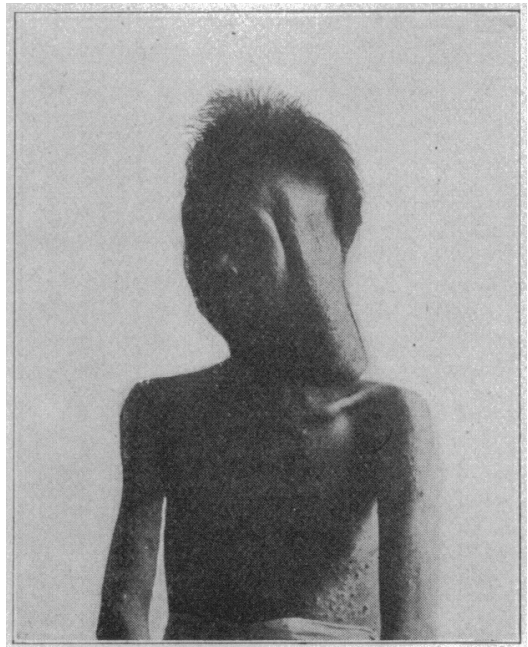

Fig. 2.-Front view of patient in Fig. 1.

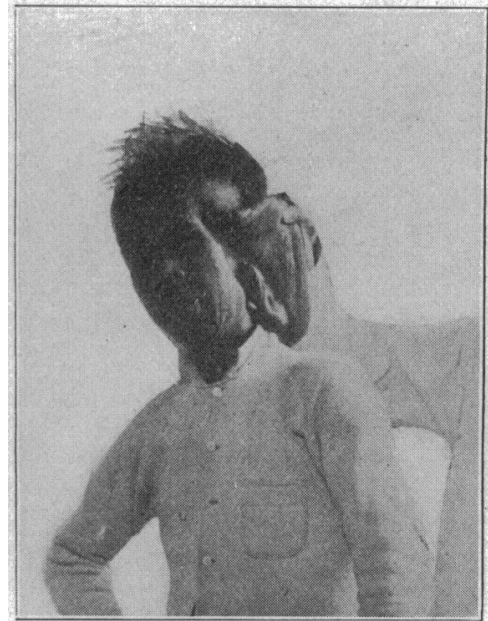

Fig. 3.-Flap of skin lifted to show ear. in Stelwagon's Diseases of the Skin as a hypertrophy and looseness of the skin and subcutaneous connective tissue with a tendency to hang in folds, and has been spoken of as "loose skin," "cutis laxa," "cutis pendula" or "chalazodermia." It may be congenital or acquired. All parts of the skin share , in the hypertrophy; it may be located in any part of the cutaneous surface of the body. There are no subjective symptoms and it is slowly progressive. The etiology is obscure though the disease sometimes begins at the site of an injury.

The condition shows no tendency to decrease but rather to develop. Operative measures have been employed successfully when the hypertrophied flap of skin was troublesome.

It appears that fibromatosis is sometimes associated with dermatolysis, as in one of the cases cited below. In fact, the relationship of these two conditions seems to be not unusual.

CASE 1.-P. S. O.; a Chinese farmer, aged 33, was admitted to the hospital of the University Medical School, Canton, China, March 25, 1914, complaining of gastric distress, which was later diagrosed as gastric ulcer. Of rather slight build the patient presented a remarkable appearance on account of a large cutaneous flap hanging over the left side of his face. Over the back, chest and abdomen there were numerous fibrous tumors varying in size from that of a millet seed to a raised up and the ear projecting from the inner surface disclosed (Fig. 3).

CASe 2.-L. K., Chinese, aged 20, was admitted to the Canton Hospital in May, 1914, in order to care for a relative who was operated on for stone in the bladder. L. K. is not ill. When 5 years old he developed an abscess of the scalp behind and below the right ear and about 3 inches distant from it. The scar of this abscess is still visible. Ten years later he noted swelling of the scalp in this region. This has gradually increased so that at present the loose flap of skin extends 3 inches above the right ear, 2 inches below and is altogether 4 inches wide (Fig. 4). It is continuous with the tissues of the scalp, is slightly elastic and is not pendulous as in the former case. It is covered with hair. Patient feels no discomfort. The flap is said to be gradually increasing in size.

These two cases of dermatolysis, both of the scalp, represent the congenital and acquired form. In both cases the subject was below the average of intelligence. Neither was willing to have the redundant skin removed.

Canton Christian College.

Preventogram.-An hour's prevention may save a month of quarantine.-Pittsburgh City's Health. 